Original Research Article

\title{
An observational study of various drug promotional advertising brochures: with an emphasis on World Health Organization ethical criteria for medicinal drug promotion
}

\author{
Ervilla Dass*
}

Department of Pharmacology, Smt. Bhikhiben Kanjibhai Shah Medical Institute \& Research Centre, Sumandeep Vidyapeeth an institution deemed to be University, At. \& PO. Piparia, Waghodia, Vadodara 391760, Gujarat, India

Received: 25 May 2018 Accepted: 29 May 2018

*Correspondence to: Dr. Ervilla Dass, Email: ervilladass@gmail.com

Copyright: (C) the author(s), publisher and licensee Medip Academy. This is an openaccess article distributed under the terms of the Creative Commons Attribution NonCommercial License, which permits unrestricted noncommercial use, distribution, and reproduction in any medium, provided the original work is properly cited.

\begin{abstract}
Background: Drug promotional literature (DPLs) is an integral approach of pharmaceutical marketing strategy, which can almost influence a physician to prescribe definite variety of medicine from a particular company. The objective was to evaluate the accuracy, consistency, and validity of the information in accordance with the World Health Organization (WHO) ethical criteria for medicinal drug promotion.

Methods: This was an observational study, in which total 100 DPLs were sorted out to evaluate whether the information is consistent/relevant with that presented by the criteria laid down by the WHO guidelines; such as nature of claims, pictorial content presented, cited references, the indication and significance of various data such as figure, graphs, table and clinical data.

Results: From all the 100 promotional literatures sorted out, all showed the INN name and brand name, amount of active ingredient, dosage form and name and address of manufacturers/distributers was shown in all; adjuvants known to cause problem were not shown. Moreover, approved therapeutic uses were clearly mentioned in 35, 48 were having pictures presented, scientific graphs and clinical data were shown in 19.

Conclusions: The results reveal that, majority of DPLs satisfied only half of the WHO criteria for rational drug promotion and none of them fulfilled all the specified criteria. Incomplete or exaggerated information in DPLs may mislead and result in irrational prescription. Therefore, physicians should critically evaluate DPLs regarding updated scientific evidence required for quality patient care.
\end{abstract}

Keywords: Advertising brochures, Drug promotion, Promotional literatures, WHO guidelines

\section{INTRODUCTION}

Promotion of a medicament or any pharmaceutical product involves pharmaceutical companies' major marketing technique through their eloquent communication skills which is directed to physician. Extensive scientific investigation of drugs in man and introduction of numerous new drugs over the past few decades is gradually transforming the practice of medicine from "experience based" wherein clinical decisions are based on the experience (or rather impression) of the physician to "evidence based" wherein the same are guided by scientifically credible evidence from well designed clinical studies. Today's physician has to be skilled in searching and evaluating the literature on efficacy, safety and appropriateness of a particular therapeutic measure. ${ }^{1}$

The main objective of ethical criteria for medicinal drug promotion is to support and encourage the improvement of health care through the rational use of medicinal drugs. They apply to prescription and non-prescription medicinal drugs also known as over-the-counter drugs. Generally, WHO criteria can also be applied to traditional medicines as appropriate, and to any other medicament. The criteria 
could be used by people in all walks of life; by governments; the pharmaceutical industry (manufacturers and distributors); the promotion industry (advertising agencies, market research organizations and the like); and health personnel. ${ }^{2}$

In drug advertisements, pharmaceutical manufacturers have an opportunity to proclaim the existence of a drug, promote its advantages, and also provide useful information to help a clinician to decide whether and when to use the medicine. Three main types of printed drug advertisements such as; handouts/booklets that are given by medical representatives, advertisements in periodicals, and individual direct mail advertisements. It plays a crucial role in keeping the physicians updated about various aspects of pharmaceutical products and the newer therapeutic modalities, helping them provide the most appropriate solution for treating the patients. As per World Health Organization (WHO), definition drug promotion is 'all informational and persuasive activities by manufacturers and distributors, the effect of which is to induce the prescription, supply, purchase, and/or use of medicinal drug. WHO has published ethical criteria for medicinal drug promotion in the year 1988 to evaluate the appropriateness of promotional drug literatures and has recommended pharmaceutical industries to implement this guideline. ${ }^{3,4}$

Drug promotional literature (DPL) includes product characteristics, side effects, dosage regime, contraindications and various marketing claims with references which at times, may be inadequate, deceptive and of poor educational value. These lapses in the field of ethics are a matter of immense concern for the past few decades. Some observational studies have observed that information provided in DPLs is varying with the code of ethics, which can affect the drug utilization and prescription. Ethical criteria for medicinal drug promotion by World Health Organization, 1988; is thought to be the foundation of self-administrative code of International Federation of Pharmaceutical Manufacturers and Associations (IFPMA) as well as Organization of Pharmaceutical Producers of India (OPPI), a selfregulatory code of pharmaceutical marketing practices, December 2012. The rationality of drug promotional literature can be assessed by considering World Health Organization criteria for ethical medicinal drug promotion, $1988 .^{5-7}$

Hence, this study was conducted to critically assess the accuracy of the Drug Promotional Advertising Brochures or DPL, and to find out the accuracy, detail information presented and evidence-based information from different pharmaceutical companies, using the ethical criteria for medicinal drug promotion from WHO.

\section{METHODS}

Drug Promotional Advertising Brochures from various pharmaceutical/marketing companies in India were collected, during a period of two years. This observational, cross-sectional study was conducted after its approval by the Institutional Ethics Committee. Drug Promotion literatures were sorted from various pharmacological drug class such as Antibiotics, Ophthalmology, drugs acting on Central Nervous System, drugs acting on Cardiovascular System, drugs acting on Autonomic Nervous System, Autacoids, drugs acting on Respiratory system, drugs acting on Gastrointestinal System, diuretics, and others. Out of total 143 DPLs collected for this present study, total 100 drug promotional materials were sorted out and were included in the study; other 43 materials for drug promotion were excluded from the study, such as detail aid brochures, slimmer version of flyer, flash card, pocket guides, and commercial newsletters/bulletin.

Further, from the sorted 100 DPLs, were analysed to assess types of claims presented, pictorial presentations, references quoted, the indication and significance of various data such as figure, graphs, table and clinical data, presented in the drug promotional literature and analysis was done and reviewed by using a standardized proforma as indicated below; based on WHO guidelines, Ethical criteria for medicinal drug promotion, 1988, to collect data and perform an Evidence-Based review of the various drug promotional literatures, comparing data that are presented in the brochure with those in standard non-commercial source of information of drugs (Pharmacopoeias, Martindale, British National Formulary, national formulary of India, and standard medical subject speciality textbooks). The data were expressed as percentage.

The promotional literature should contain the below mentioned information based on WHO criteria:

- The names of the active ingredients using either international non-proprietary names or the approved generic names of the drug

- $\quad$ The brand names

- Content of active ingredient per dosage form or regimen

- Name of other ingredients known to cause problems, i.e., adjuvant

- $\quad$ Approved therapeutic uses

- Dosage form or regimen

- $\quad$ Side effects and major adverse drug reaction

- $\quad$ Precautions, contraindications, and warnings

- Major interactions

- Name and address of the manufacturer or distributor

- $\quad$ Reference to scientific literature as appropriate.

\section{RESULTS}

Drug Promotional Advertising Brochures which were included in the observational study, total $100(n=100)$, were most commonly promoted drug categories/or systemwise included from pharmacological drug class of hormonal drugs 18 DPLs, Central nervous system 07 DPLs, Autocoids and Non-steroidal anti-inflammatory 
drugs (NSAIDs) 12 DPLs; Gastrointestinal tract system 24 DPLs; Respiratory system 27 DPLs; Cardiovascular system 12 DPLs; which is depicted in Figure 1.

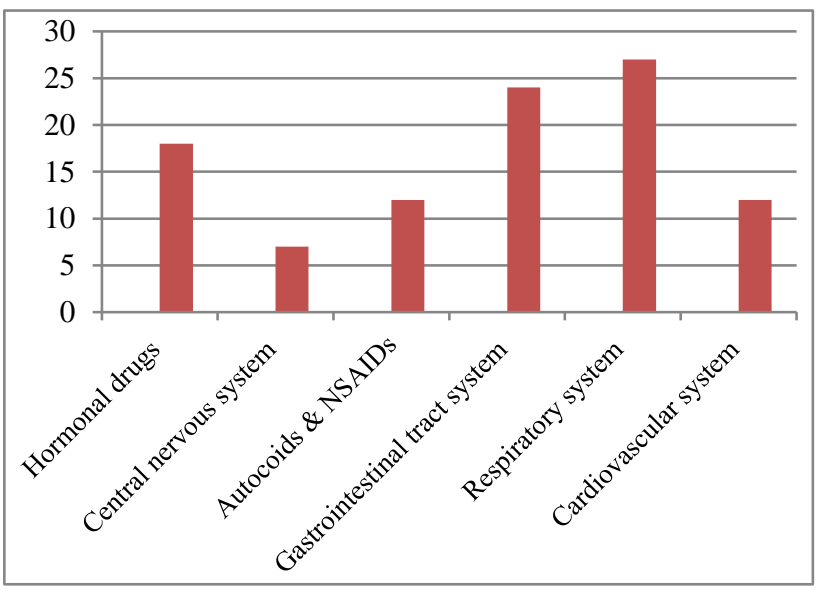

\section{Figure 1: Number of drug promotional advertising brochures evaluated based on pharmacological drug class.}

Further, all the DPLs were evaluated according to the World Health Organization criteria $(n=100)$ which is shown in Table 1 . It was observed that the names of the active ingredients using either international nonproprietary names or the approved generic names of the drug; the brand name and the name and address of the manufacturer or distributor were mentioned in all 100 DPLs. Whereas, the least mentioned information was regarding Name of other ingredients known to cause problems, i.e., adjuvant $(07 \%)$ and major interactions (09\%). Other contents such as content of active ingredient per dosage form or regimen was observed in $92 \%$ of DPLs, approved therapeutic uses $82 \%$, out of which only in 35 DPLs out of 82 DPLs, the approved therapeutic uses specifically were clearly highlighted and were prominent. Dosage form or regimen $84 \%$; side effects and major adverse drug reaction $12 \%$, precautions, contraindications, and warnings $23 \%$ and reference to scientific literature as appropriate $27 \%$ were observed. In 48 DPLs it was observed that they showed relevant pictures presented and relevant scientific graphs. Clinical data were presented in 19 Drug Promotional brochures which were analysed.

Moreover, apart from these criteria, the size, the readability or legibility and colour contrast of the information materials were also evaluated. It was observed that a DPL was sizable if it was equal or greater than A4sized paper; legible if the font size is equal to or more than 12; good colour contrast if the material had white/light or contrasting background with the printed matter. Further, it was also observed that the photographs occupied considerable amount of space on all DPLs which were mostly irrelevant such as nature, home, vehicles, instruments, and majority were showing human body/organ, hospital setups or operation theatre. Some of them also showed statistical data pertaining to clinical trials. Pharmaceutical industries cited references from medical journals to support information presented or claims made in the Drug promotional literature.

\section{Table 1: Analysis of drug promotional literatures according to the World Health Organization criteria $(\mathbf{n}=\mathbf{1 0 0})$.}

\begin{tabular}{|ll|}
\hline $\begin{array}{l}\text { Content based on WHO } \\
\text { criteria }\end{array}$ & $\begin{array}{l}\text { DPLs fulfilling the } \\
\text { WHO criteria } \\
\text { [Percentage (\%)] }\end{array}$ \\
\hline $\begin{array}{l}\text { The names of the active } \\
\text { ingredients using either } \\
\text { international non-proprietary } \\
\text { names or the approved generic } \\
\text { names of the drug }\end{array}$ & 100 \\
\hline The brand name & 100 \\
\hline $\begin{array}{l}\text { Content of active ingredient } \\
\text { per dosage form or regimen }\end{array}$ & 92 \\
\hline $\begin{array}{l}\text { Name of other ingredients } \\
\text { known to cause problems, i.e., } \\
\text { adjuvant }\end{array}$ & 07 \\
\hline Approved therapeutic uses & 82 \\
\hline Dosage form or regimen & 84 \\
\hline $\begin{array}{l}\text { Side effects and major adverse } \\
\text { drug reaction }\end{array}$ & 12 \\
\hline $\begin{array}{l}\text { Precautions, contraindications, } \\
\text { and warnings }\end{array}$ & 23 \\
\hline Major interactions & 09 \\
\hline $\begin{array}{l}\text { Name and address of the } \\
\text { manufacturer or distributor }\end{array}$ & 100 \\
\hline $\begin{array}{l}\text { Reference to scientific } \\
\text { literature as appropriate }\end{array}$ & 27 \\
\hline
\end{tabular}

\section{DISCUSSION}

Drug promotional literatures are an important means of bringing drug information to health care professionals. Their primary goal is to convince clinicians to prescribe their products. Drug promotional literature is one of the well known promotional activities of pharmaceutical or marketing industries which are many times inaccurate and of poor educational value. In drug promotional literature, just because each of the categories of information is present in an advertisement does not necessarily mean that the advertisement will give a complete picture of the medicines safety and effectiveness and how to prescribe the medicine appropriately. These promotional activities create the potential for inappropriate prescribing practice by influencing physicians prescribing behaviour, hence, ethical promotion of medicines is important in order to ensure that medicines are prescribed and used in a rational way. Information about medicines is necessary to help prescribers to practice rational drug therapy.

Pharmaceutical companies should provide reliable information in promotional literature which is essential for rational prescribing as recommended by $\mathrm{WHO}^{2}$ 
The predominance of pseudo-graphs pointed out the commercial and promotional rather than educational attitude of the industries. The findings were similar to the observations made in other studies; where author found broad unscientific, dubious claims in Drug promotional literature which is depriving the physicians of authentic drug information. ${ }^{8-10}$ Printed promotional materials is an important source of drug information. On the basis of the observations of this study, it is suggested that physicians need to be aware of the flaws in promotional literature before accepting it as valid information.

Though majority of the Drug promotional literature were attractive, but had irrelevant pictures related to the drugs being promoted. DPLs had used nonspecific representations occupying major area, which could have been utilized appropriately for relevant clinical and pharmacological information, listing various properties of drugs, other studies have reported similar finding. In DPL, the claim must be consistent with cited research and the research should be designed with adequate methodology. More recent work analysing advertisements in India, Brazil and the Russian Federation shows that they continue to leave out essential information recommended by WHO. Just because each of the categories of information is present in an advertisement does not necessarily mean that the advertisement will give a complete picture of the medicine's safety and effectiveness and how to prescribe the medicine appropriately. ${ }^{11}$

The WHO Criteria clearly states that promotion of drugs in all forms should be fully consistent with the approved scientific data sheet for the medicine concerned or other source of information with similar content should at least contain summary of scientific information. Many observational research studies have noted that, such DPLs were mostly intended to promote the brand rather than to educate or give information to the physician. ${ }^{12}$ Therefore, a step that must be taken to overcome the problem is to develop awareness programs that will teach future prescribers/physicians, the necessary skills to critically appraise promotional materials. As promotion of drug product can change prescribing behaviours of the health professionals, the messages of promotion should be factual, evidence-based, unambiguous and balanced. ${ }^{13}$

\section{CONCLUSION}

Printed promotional literatures and visual aids are considered as important source of information for the physicians. The conclusion can be drawn that the pharmaceutical companies promote the brand names and the information regarding adverse effect is lacking. Few literatures show the information on therapeutics which is provided to help the physician to take decision about that medicine. Claims made on safety basis are therapeutically irrelevant or misleading. Therefore, it is the need of hour for some remedial measures to this issue such as prescriber's awareness generation, reinforcement of existing laws, and development of guidelines and their implementation by pharmaceutical companies for drug promotion.

\section{ACKNOWLEDGEMENTS}

Author is grateful to Smt. Bhikhiben Kanjibhai Shah Medical Institute and Research Centre, Sumandeep Vidyapeeth an Institution deemed to be University, Piparia, Vadodara, for permitting to conduct the study.

Funding: No funding sources Conflict of interest: None declared

Ethical approval: The study was approved by the Institutional Ethics Committee of Sumandeep Vidyapeeth (SVIEC), Sumandeep Vidyapeeth Deemed to be University, Piparia, India

\section{REFERENCES}

1. Essentials of medical pharmacology. Chapter 5: Aspects of pharmacotherapy; clinical pharmacology and drug development, page $71 ; 6^{\text {th }}$ edition, Jaypee Publication, New Delhi; 2008.

2. Ethical criteria for medicinal drug promotion. World Health Organization, 1988. Available at: http://apps.who.int/medicinedocs/documents/whozip 08e/whozip08e.pdf. Cited on 2016 March.

3. Kaushal S, Singh J, Biswas A. A critical appraisal of drug advertisements and their impact on prescribing: An observational, cross-sectional study. Anaesth Pain and Intensive Care. 2015;19(4):489-94.

4. Sahne BJ, Yegenoglu S, Uner M, Wertheimer AI. Adherence of drug advertisements to the international marketing codes. Hacettepe University $\mathbf{J}$ of the Fac of Pharma. 2012;32(1):53-66.

5. Alam K, Shah AK, Ojha P, Palaian S, Shankar PR. Evaluation of drug promotional materials in a hospital setting in Nepal. South Med Rev. 2009;2:2-6.

6. Cooper RJ, Schriger DL. The availability of references and the sponsorship of original research cited in pharmaceutical advertisements. CMAJ. 2005;172:487-91.

7. Organization of Pharmaceutical Producers of India (OPPI); 2012. Available at: https://www.indiaoppi.com/sites/default/files/PDF\%2 Ofiles/For-Download-OPP-Handbook-05-09-

2017_0.pdf. Cited on 2016 Feb 03.

8. Garje YA, Ghodke BV, Lalan HN, Senpaty S, Kumar R, Solunke S. Assessment of promotional drug literature using World Health Organization guidelines. Int J Ayurveda Res. 2014;4:3-5.

9. Cardarelli R, Licciardone JC, Taylor LG. A crosssectional evidence-based review of pharmaceutical promotional marketing brochures and their underlying studies: Is what they tell us important and true? BMC Family Practice. 2006;7:13.

10. Cooper RJ, Schriger DL, Wallace RC, Mikulich VJ, Wilkes MS. The quantity and quality of scientific graphs in pharmaceutical advertisement. J Gen Intern Med. 2003;18:294-7. 
11. Understanding and Responding to Pharmaceutical Promotion. A Practical Guide. First edition World Health Organization/Health Action International Collaborative Project. Available at: http://www1.paho.org/hq/dmdocuments/2011/drugpromotion-manual-CAP-3-090610.pdf. Cited on 14 October, 2015.

12. Prosser H, Almond S, Walley T. Influences on GPs' decision to prescribe new drugs- the importance of who says what. Family Practice. 2003 Feb;20(1):61-8.
13. Villanueva P1, Peiró S, Librero J, Pereiró I. Accuracy of pharmaceutical advertisements in medical journals. Lancet. 2003 Jan 4;361 (9351):27-32.

Cite this article as: Dass E. An observational study of various drug promotional advertising brochures: with an emphasis on World Health Organization ethical criteria for medicinal drug promotion. Int $\mathbf{J}$ Basic Clin Pharmacol 2018;7:1280-4. 